\title{
ESTÁGIO EXTRACURRICULAR E EDUCAÇÃO INCLUSIVA: DILEMAS E PERCEPÇÕES DE ALUNAS DO PRIMEIRO ANO DE UM CURSO DE PEDAGOGIA
}

\author{
Ana Paula de Freitas ${ }^{\mathrm{i}}$ \\ Débora Dainez ${ }^{\text {ii }}$
}

\begin{abstract}
Resumo: Na esteira das políticas inclusivas, ações voltadas às formas de organização escolar para assegurar o acolhimento educacional de alunos com deficiência têm sido realizadas. Dentre essas ações, municípios têm contratado estagiários de cursos de licenciaturas para acompanhamento de alunos com deficiência na sala de aula comum. Neste artigo, investigamos, a partir dos dizeres de alunas de um curso de Pedagogia que realizam estágio extracurricular, seus modos de participação na dinâmica da sala de aula em que há alunos com deficiência, atentando-nos às funções que lhes são atribuídas e aos dilemas enfrentados no cotidiano escolar. Examinamos, ainda, suas percepções em relação aos processos de ensino-aprendizagem da criança com deficiência.
\end{abstract}

Palavras-chave: Educação Inclusiva. Formação Docente Inicial. Estágio Extracurricular. Pedagogia.

\section{EXTRACURRICULAR INTERNSHIP AND INCLUSIVE EDUCATION: DILEMMAS AND PERCEPTIONS OF STUDENTS OF THE FIRST YEAR OF A PEDAGOGY COURSE}

\begin{abstract}
In the wake of inclusive policies, actions have been taken towards the forms of school organization to ensure an adequate reception from the educational stand point for the students with disabilities. Among these actions, municipalities have been hiring undergraduate interns to accompany students with disabilities in regular classrooms. In this paper, we investigate a group of students from a pedagogy course that works as interns on classes that have students with disabilities, with particular attention to the roles they have been given and to dilemmas they face on the regular school days. We also examine their perceptions related to the teaching-learning processes for students with disabilities.
\end{abstract}

Key words: Inclusive education. Initial Teacher Training. Extracurricular Internship. Pedagogy.

\section{Introdução}

Nos últimos anos, a política educacional brasileira, com base nos direcionamentos internacionais que promulgam a universalização da educação básica nos países em desenvolvimento, vem adotando a perspectiva inclusiva (PLETSCH, 2014). Nesta linha, tem sido proposta iniciativas visando o aumento dos índices de matrículas em todos os níveis de escolaridade e a expansão da obrigatoriedade escolar (KASSAR, 2016), de modo a garantir a 


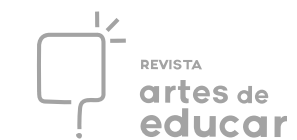

inserção de grupos historicamente marginalizados ao sistema educacional. A meta é acolher todas as crianças na faixa etária adequada à educação básica, viabilizando recursos para atender as necessidades específicas de aprendizagem. Neste sentido, as políticas educacionais brasileiras, mais precisamente aquelas voltadas à educação especial, estão orientadas para a transformação do sistema educacional em sistema educacional inclusivo, com ênfase no acesso e permanência de alunos com deficiência, transtornos globais do desenvolvimento e altas habilidades/superdotação nas escolas regulares.

Conforme pontuam Oliveira e Leite (2007), a concretização do sistema educacional inclusivo demanda um planejamento complexo que engloba desde ações macrossistêmicas, passando por ações no âmbito político-pedagógico decorrente da administração assumidas pelo município, até ações pontuais implementadas no cotidiano da sala de aula.

Parâmetros e recursos são fornecidos através de programas federais, que visam apoiar os sistemas de ensino na organização da oferta do atendimento educacional especializado, na implantação de salas de recursos multifuncionais nas escolas de educação básica, na ampliação do processo de formação de gestores e na oferta de formação continuada de professores (BRASIL, 2001; BRASIL, 2005; BRASIL, 2008). Na esteira dessas políticas, novas demandas são delineadas assim como responsabilidades são redefinidas, confrontando os arranjos das redes municipais. Conforme apontado nos trabalhos de Prieto et al (2004) e Garcia (2008), os municípios têm se organizando de formas variadas, dentre as quais se destaca a preocupação com a criação de serviços especializados de atendimento educacional e se acentua as parcerias ou convênios com instituições privado-assistenciais de atendimento especializado.

Diante dos desafios que permeiam a implantação do sistema educacional inclusivo, há movimentos na esfera municipal para instituir ações de suporte pedagógico com vistas em assegurar a escolarização do público-alvo da educação especial. A contratação de estagiários dos cursos de licenciaturas, de pedagogia para acompanhamento sistemático de alunos com deficiência na sala de aula comum tem sido uma dessas ações emanadas da ampliação do ingresso desse alunado no sistema regular de ensino. Essa questão foi evidenciada na pesquisa de Prieto et al (2014) que teve como propósito identificar as ações propostas pelo município de São Paulo no sentido de favorecer a inclusão escolar. Dentre os apontamentos, as autoras constatam a problemática de deslocamento das atribuições do professor regente da classe comum para o estagiário. A partir dos resultados do estudo, indicam a necessidade de assegurar e consolidar intervenções de formação para os diferentes participantes da comunidade escolar (gestores, professores regentes e de educação especial, funcionários técnico-administrativos, estagiários, auxiliar de vida escolar/cuidador). 
Praticamente a mesma realidade foi observada nos estudos de Oliveira e Pinto (2011), que tratou de compreender a contribuição do estágio extracurricular na formação dos futuros professores. As autoras constatam que apesar de os estagiários, nessa experiência, avançarem na prática educativa com alunos com deficiência na classe comum, tal prática apresenta limites por se construir à parte da dinâmica geral da própria sala de aula. Ao invés de os estagiários atuarem junto aos professores e serem, por eles, acompanhados, acabam por cuidar dos alunos com deficiência.

Considerando esse cenário, a proposta deste trabalho emerge da demanda de alunas do primeiro ano de um curso de pedagogia que realizam estágio extracurricular em uma rede de ensino municipal de uma cidade do Estado de São Paulo, na Educação Infantil e no Ensino Fundamental, e estão sendo designadas para atenderem as salas de aula que têm alunos com deficiências matriculados sem, contudo, receberem orientações específicas a esse fim.

Em visto disso, as alunas estagiárias tomam a iniciativa de solicitar auxílio aos professores do curso para poderem desenvolver o estágio. Uma das professoras, que realiza pesquisas na área da Educação Especial, assume então a tarefa de coordenar um grupo de estudos com essas alunas, em caráter de atividade complementar, com o intuito de construir um espaço de discussão e reflexão sobre a experiência pedagógica vivida no cotidiano escolar, abrangendo tópicos de debates como o papel do estagiário e as funções atribuídas, as concepções e os processos de ensino-aprendizagem envolvendo a criança com deficiência.

Desta forma, com base nessa experiência, delineamos como objetivo neste texto investigar, a partir dos dizeres das próprias alunas estagiárias, seus modos de participação na dinâmica da sala de aula em que há alunos com deficiência, atentando-nos às funções que lhes são atribuídas e aos dilemas enfrentados no cotidiano escolar. Em um segundo momento, buscamos examinar as percepções das alunas estagiárias em relação aos processos de ensinoaprendizagem da criança com deficiência.

Esperamos, assim, contribuir com as discussões acerca das ações políticas voltadas às formas de organização escolar para assegurar o acolhimento educacional de alunos com deficiência e com o debate sobre a formação inicial de professoras no âmbito das licenciaturas em Pedagogia.

\section{O percurso e o procedimento metodológico}

Este artigo se insere no contexto de uma pesquisa em andamento que visa identificar como nos processos de intersubjetividade ocorrem as condições de possibilidades de ensinar e Revista Interinstitucional Artes de Educar. Rio de Janeiro, V. 4, N.1- pág. 79 - 100 - (jan. - abr. de 2018): "Questões contemporâneas sobre a Educação Especial na Perspectiva da Educação Inclusiva" - 
aprender na escola ${ }^{1}$, com foco para o processo de escolarização de alunos com deficiências. Os dados que estão sendo construídos durante os encontros do grupo de estudo anteriormente referido são tomados como material de análise dessa pesquisa.

Neste texto, portanto, apresentamos recortes de situações vivenciadas em um grupo de estudos que funciona em caráter de atividades complementares em um curso de pedagogia de uma universidade privada-comunitária, localizada em uma cidade do interior paulista. Como já mencionamos, esse grupo surgiu em função da demanda de alunas que estão realizando estágio extracurricular em uma rede municipal de ensino e estão assumindo a tarefa de acompanharem os alunos com deficiências matriculados nas salas comuns.

O estágio extracurricular se efetiva como uma forma de apoio oferecida pelo município no sentido de implantar práticas educativas inclusivas. As alunas do curso de pedagogia participaram de um processo seletivo e foram contratadas como estagiárias. O contrato é de 20 horas semanais. A organização e a supervisão desse estágio estão sob responsabilidade de um centro de atenção educacional do município. Esse centro é formado por uma equipe multidisciplinar que conta com profissionais como psicóloga, psicopedagogos, fonoaudiólogos, fisioterapeutas. Tem como objetivo subsidiar a rede municipal de ensino, assessorando as unidades escolares a fim de garantir a inclusão escolar de alunos. Dentre suas principais ações, estão aquelas relacionadas às orientações e suportes aos auxiliares de classe; triagens e encaminhamentos de alunos a outros especialistas; trabalho de atendimento e de prevenção aos alunos; realização de avaliação psicológica de alunos com possíveis dificuldades de aprendizagem; formação para os professores das salas de recursos; adequação de espaço físico, material e oferta de recursos específicos para o atendimento educacional especializado; atendimento e orientação às famílias. Mensalmente, profissionais desse setor realizam um encontro para discutirem sobre o andamento dos estágios e passarem orientações sobre as funções das estagiárias.

Todas as alunas que cursam pedagogia na referida universidade e que realizam esse estágio extracurricular, iniciado pela maioria delas em abril de 2017 , foram convidadas a fazer parte do grupo. Sete alunas tiveram disponibilidade de participar no momento. Desse modo, desde maio de 2017, elas e a professora se reúnem quinzenalmente, durante 90 minutos, para discutirem sobre as situações vivenciadas durante os estágios, e para estudarem sobre a temática

\footnotetext{
${ }^{1}$ Projeto Temático: A constituição de educadores e alunos no contexto das práticas sociais escolares, sob coordenação de (primeira autora), que se insere no contexto do grupo de pesquisa Relações de Ensino e Trabalho Docente (diretório CNPq).
} 


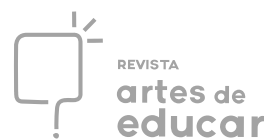

do ensino para alunos com deficiência no contexto das políticas de inclusão escolar. Como já dissemos anteriormente, as alunas estão no primeiro ano do curso de pedagogia e têm idade entre 17 e 21 anos. As reuniões são audiogravadas e, posteriormente, transcritas.

As estagiárias V. e D. realizam estágio na educação infantil. V acompanha o aluno L.G., com três anos, com paralisia cerebral. A estagiária D. acompanha K., com três anos, com Síndrome de Down. As estagiárias G., N., I., B. e A.L. realizam estágio no ensino fundamental. G. está responsável pelo acompanhamento da aluna L., com oito anos, no segundo ano, diagnosticada com a síndrome do espectro do autismo e deficiência intelectual. N. acompanha o aluno LU., com oito anos, que está no terceiro ano e tem diagnóstico de transtorno do déficit de atenção e hiperatividade (TDAH). I. está em uma sala do sexto ano e acompanha dois alunos: M., com dislexia e TDAH e T., sem diagnóstico, mas com dificuldades de aprendizagem. B. acompanha o aluno W., com 12 anos, diagnosticado com deficiência intelectual, deficiência auditiva e epilepsia, no $4^{\text {o }}$ ano do ensino fundamental. A.L. acompanha os alunos A.B. e R., ambos com 11 anos e, respectivamente, com deficiência intelectual e TDAH, no $5^{\circ}$. ano do ensino fundamental.

Para este texto, selecionamos alguns segmentos dos dizeres registrados escolhidos em função de fornecerem elementos para a análise dos modos de participação das estagiárias nas salas de aula em que há alunos com deficiência, e dos modos como significam o trabalho de ensino para/com esses alunos. Sendo assim, organizamos as situações em duas unidades temáticas: 1. Das funções e atribuições: desafios nos modos de participação das estagiárias na dinâmica da aula no contexto da educação inclusiva e 2. Das percepções de ensino-aprendizagem de alunos com deficiência.

A partir de uma perspectiva histórico-cultural do desenvolvimento humano, de acordo com Vigotski (2000a, p. 17), consideramos que o método deve permitir “...não só revelar a unidade interna do pensamento e da linguagem como ainda estudar, de modo frutífero, a relação do pensamento verbalizado com toda a vida da consciência em sua totalidade e com as suas funções particulares". Isso quer dizer que os dizeres dos sujeitos carregam sentidos que se produzem nas relações e atividades coletivamente desenvolvidas; que refletem e refratam os lugares ocupados e os papeis desempenhados no grupo social, e são permeados das contradições produzidas historicamente em determinada forma de organização da sociedade.

Para fins analíticos, procedemos de modo a buscar, no movimento discursivo instaurado durante os encontros do grupo, os sentidos que vão sendo produzidos e transformados nesse movimento. Em consonância com as ideias de Bakhtin (1995) e Vigotski (2000a) focalizamos o papel privilegiado da palavra no processo de (re)elaboração de conhecimentos partilhados no Revista Interinstitucional Artes de Educar. Rio de Janeiro, V. 4, N.1- pág. 79 - 100 - (jan. - abr. de 2018): “Questões contemporâneas sobre a Educação Especial na Perspectiva da Educação Inclusiva” - 
espaço da intersubjetividade. Ela se constitui nas/pelas relações intersubjetivas. Pela palavra, situados em práticas sociais, os sujeitos se constituem e elaboram seus conhecimentos. Para esses autores, o sentido das palavras não é único, é fluído, determinado pela situação. Sobre a questão, Bakhtin (2003, p. 410) afirma não haver limites para o contexto dialógico:

Em qualquer momento do desenvolvimento do diálogo existem massas imensas e ilimitadas de sentidos esquecidos, mas em determinados momentos do sucessivo desenvolvimento do diálogo, em seu curso, tais sentidos serão relembrados e reviverão em forma renovada [...] cada sentido terá sua festa de renovação.

Desse modo, nas análises focalizamos o movimento discursivo das alunas e da professora, buscando construir sentidos possíveis para os seus dizeres, tendo em vista, as condições históricas, socioculturais e políticas dessa produção.

\section{Das funções e atribuições: desafios nos modos de participação das estagiárias na dinâmica da aula no contexto da educação inclusiva}

Encontro: 08.08.2017.

Participantes: estagiaria G., estagiaria V., estagiaria D., estagiaria I., estagiaria B., doutoranda L., aluna e auxiliar de uma escola particular M., professora pesquisadora.

Contexto: A professora pesquisadora retoma o assunto sobre as orientações recebidas para iniciar o estágio e sobre a formação específica para essa atividade.

Est.G.: A gente tem a formação uma vez por mês, que assim, não ensina a gente a lidar com os alunos. Fala tipo como se comportar sendo um auxiliar de classe.

$[\ldots]$

Est.V.: [...] Não nos orienta. É mais ou menos assim, você está aí só pra vigiar...

$[\ldots]$

Prof. Pesq.: Quem dá a formação para vocês?

Várias alunas respondem ao mesmo tempo que é uma equipe de um centro associado à rede municipal formada por uma psicopedagoga, uma fisioterapeuta e uma fonoaudióloga.

Est.D.: E também aquela coisa assim, não são dez pessoas, são quarenta pessoas na mesma formação, [...] são todas as estagiarias de pedagogia...

Prof. Pesq.: Quanto tempo é essa formação?

Várias estagiarias falam ao mesmo tempo, informam que o tempo de formação é de quatro horas, uma vez por mês.

$[\ldots]$

Prof. Pesq. pergunta sobre as recomendações/orientações dadas na formação.

Est.G..: Não criar laço afetivo com os alunos, não pode falar com os pais...

$[\ldots]$

Est.V.: Tipo assim ó, a gente está em sala de aula e o aluno tem dificuldade nisso. Eles dizem para você não passar lição, não orientar o aluno, porque isso cabe ao professor e não a você. Só 
que em sala de aula [...] se não auxilia o aluno, a professora deixa o aluno a ver navios. Isso é muito contraditório.

$[\ldots]$

Est. I.: Eu, por exemplo, a professora fala assim 'Ai eu tenho mais vinte alunos pra focar, então você fica com ele e eu vou ficar com os outros. Daí se você precisar de mim, você dá um grito'.

$[\ldots]$

Est. V.: A minha relação com a professora é ótima, eu falo assim que ela me ensina mais do que a formação.

Várias alunas falam ao mesmo tempo: As professoras acabam ensinando mais a gente do que a formação.

Est.V.: É no dia a dia as professoras falam né, 'Ó isso aqui é melhor você não fazer, ah isso aqui é legal você fazer. Ó não faça isso quando você for professora'. [...]. Ainda bem, né? E às vezes tem algumas situações que você, que a professora lida de um jeito e você fala nossa isso foi muito dá hora, ou nossa isso eu não vou fazer. Então você acaba aprendendo mais com a professora do que...

Prof. Pesq.: do que na formação.

Est.V: É porque na formação[...]. Eu acho que na formação elas não tem o jeito da sala de aula, não sabem como que é.

Encontro 16.05.2017

Participantes: estagiária A.L., estagiária G., estagiaria D, professora pesquisadora.

Contexto: A estagiária A.L. conta sobre a aluna A.B com deficiência intelectual e o aluno R. com diagnóstico de Transtorno do Déficit de Atenção e Hiperatividade.

Est. A.L.: Quando eu fui lá (centro educacional) eles me falaram, você vai orientar o R. e a A.B. $\mathrm{Na}$ verdade, quando eu entrei, eu não sabia o diagnóstico da A.B. Eu entrei sem saber nada deles.

No segmento selecionado, as alunas estagiárias comentam sobre o funcionamento do estágio extracurricular e levantam os limites da "formação" recebida quando se deparam com os desafios que se produzem no cotidiano escolar. Destacam a quantidade elevada de estagiários nos encontros de orientação, o pouco tempo (1 vez por mês durante 4 horas), as recomendações voltadas para o que não deve ser feito, a falta de informação sobre os alunos com deficiência, o perfil dos profissionais formadores direcionados para o enfoque clínico e não pedagógico.

As divergências entre as recomendações recebidas e o trabalho realizado também é um ponto realçado pelas estagiárias. V. explicita a orientação dada pelo centro de não auxiliar exclusivamente o aluno com deficiência, mas a turma como um todo, atuando como forma de apoio à sala de aula. Contudo, a função que acaba exercendo na escola, de fato, é acompanhar o aluno com deficiência. A estagiária I. vivencia a mesma situação e traz em seu dizer as condições de trabalho da professora que acompanha - "Aí eu tenho mais vinte alunos pra focar". Como dar conta de todos e de cada um? Esse é um dos principais dilemas que tem perpassado a organização do trabalho pedagógico em tempos de educação inclusiva (BARRICELLI, 
DAINEZ, SMOLKA, 2016). Explicita-se o problema das condições de trabalho do professor, da estrutura e funcionamento da escola. Desta forma, de acordo com Prieto et.al (2014) a contratação de estagiários como forma de ação política-administrativa carrega o seguinte problema: "fazer com que reinvindicações históricas de diminuição de número de alunos por turma e de contratação de um profissional como auxiliar do professor fiquem reduzidas a manter estudantes nas classes acobertando essas legítimas demandas do magistério" (PRIETO ET AL, 2014, p.731).

Contudo, as estagiárias afirmam aprender com a experiência de estágio extracurricular. E mais, afirmam aprender com as professoras no chão da escola, no trabalho ombro a ombro, auxiliando, observando, ouvindo... A relação de confiança estabelecida com as professoras torna-se suporte ao trabalho das estagiárias, criando formas de proximidade com a prática pedagógica. Em outros termos, o acolhimento das professoras e as formas de mediação que se delineiam nessa relação ancoram modos de participação das estagiárias orientados para um maior contato com a dinâmica da aula, possibilitando compartilhar os desafios de implantação de práticas inclusivas. Isso vai ao encontro dos achados de Oliveira e Pinto (2011) sobre as condições de reflexão da prática educativa, sobretudo em educação especial, que esse tipo de estágio pode propiciar.

Notamos que as orientações sobre as atribuições do estágio extracurricular são passadas às estagiárias pelo centro responsável pela educação especial do município. Oliveira e Drago (2012) constatam que no município de São Paulo, a tarefa de orientar estagiários também é função da equipe de educação especial. Chama-nos, ainda, a atenção a configuração da equipe do centro educacional incumbida pela educação especial e inclusiva do município, e que é responsável pela orientação das estagiárias, pela formação de professores de apoio e pela assessoria às escolas para o atendimento aos alunos com deficiência. A equipe é constituída por especialistas, profissionais da área clínica, e não conta com uma pedagoga. A discussão e a formação de recursos humanos e materiais associados a escolarização de alunos com deficiência é de responsabilidade desses profissionais e não da escola e do professor. Neste sentido, o risco é de o aspecto clínico se sobrepor à dimensão pedagógica da educação escolar da criança com deficiência.

Sabemos que historicamente, a educação especial foi delineada partindo dos pressupostos médico-clínicos (PESSOTTI,1984; JANNUZZI,1985). Foram os médicos os primeiros a se sensibilizarem e a apostarem nas possibilidades de educabilidade da pessoa com deficiência, investigando meios para sua efetivação. Exponentes como J. Itard, E. Séguin, M. Montessori, não encontrando respostas na medicina para promover a aprendizagem e o desenvolvimento da Revista Interinstitucional Artes de Educar. Rio de Janeiro, V. 4, N.1- pág. 79 - 100 - (jan. - abr. de 2018): "Questões contemporâneas sobre a Educação Especial na Perspectiva da Educação Inclusiva" - 
criança com deficiência, se dirigiram aos princípios filosóficos pedagógicos para a delineação de uma ação educacional específica. Desta forma, na produção das ideias vemos um movimento que tangencia uma mudança de foco, da medicina para a educação (TEZZARI E BAPTISTA, 2011). Esse aspecto ainda é um desafio nos dias de hoje e se pronuncia nas experiências vividas e relatadas pelas alunas estagiarias do curso de pedagogia.

Encontro: 30.05 .2017

Participantes: estagiária G., estagiária V., estagiária N., professora pesquisadora.

Contexto: As estagiárias destacam situações ocorridas durante o acompanhamento dos alunos com deficiências e levantam algumas dúvidas em relação a isso e aos modos como devem atuar durante a realização do estágio.

Est. B.: se você fala dois mais três, ele (refere-se ao aluno W., com D.I e D.A e epilepsia) fala cinco. Se dois mais três é cinco, dois mais dois é quanto? Três. Por que assim ele volta para o três? Não dá para entender, então vamos fazer outra coisa [...] ele contou para mim, ele escreveu a história do Golfinho, ele falou que foi na festa do amigo, tinha um golfinho, ele escreveu sozinho, ele só não sabe dar espaço, mas escreveu várias palavras, o golfinho que ele escreveu 'golfio'.

Est. G.: a gente tem uma outra dúvida, a gente pode não aplicar a prova com eles? Por que se aplica a prova tem toda uma angústia na cabeça dele [...].

Est. B.: a escola fala quero que você faça, mas só de falar que é prova ele já fica irritado.

Est. V.: depende do professor, né? Nessa questão, só que aí se a gente for falar, você sabe que para o professor a gente não é nada. Já foi falado uma informação que a gente não deve... (falam ao mesmo tempo).

Prof. Pesq.: vocês estão em um papel difícil.

Todas: sim, é difícil!

Est. G.: a gente está para ajudar, só que eles não deixam a gente ajudar!

Est. V.: corrigir.

Est. G.: não é bem corrigir, mas dar ideia!

Est. V.: é, 'se você fizer desse jeito', 'tal criança ensinando desse jeito'...Só que para o professor a gente não é nada, 'você não entende e eu sei o que estou fazendo'. Sabe que nem o L.G., a gente se dá super bem, mas às vezes eu não concordo com o que ela faz algumas horas, alguns dias, assim, eu não concordo, só que ela é uma professora excelente, super excelente, nossa interação é super boa [...] Em uma reunião que teve eu participei, numa reunião da sala, eu fiquei sentada e eu ouvi tudo o que eles estavam falando e a avó dele é a responsável [...] e na reunião quando a avó veio falar um pouquinho comigo, como ele estava (refere-se ao aluno L.G.), só que eu não posso conversar, né? Só que daí é muito confuso, como fazer pra não ser mal educada, eu conversei $[\ldots]$.

Est. G.: uma coisa que eu achei muito estranha, foi uma informação que deram para a gente, que a gente não pode assumir tarefa pedagógica com os alunos, a gente não pode ensinar eles, a gente não pode dar bronca nos alunos, a gente não pode isso, a gente não pode aquilo...

(Falam ao mesmo tempo sobre o que não podem fazer)

Prof. Pesq.: só que daí é assim, né? 
(Falam ao mesmo tempo)

Est. N. [...] mas eu vejo que você fazer a atividade, traz a criança mais próximo de você, mas é algo que a gente não pode ter, de acordo com o centro educacional.

Est.G.: a gente não pode fazer nada (Falam ao mesmo tempo).

Est. V.: é tipo assim, para eles (equipe do centro) a gente só está lá de enfeite sabe, a gente está no canto da sala.

Prof. Pesq.: mas não é verdade, vocês têm que ficar com a criança de inclusão, como eles dizem! (Explica sobre a política de educação especial, na perspectiva inclusiva: os papeis do professor, do profissional de apoio e do professor do atendimento especializado)

Est. V.: isso não acontece. (Referindo-se ao que está na política)

$[\ldots]$

Est. V.: eles (equipe do centro) falam que a gente não pode ficar exclusivamente com o aluno especial, isso foi contratado no primeiro dia, e agora eles falam, você é auxiliar, o professor quer que a gente faça uma lição, a gente é obrigada a fazer...

Est. N.: assim, em questão da escola, tudo o que eles pedem eu ajudo, mesmo não sendo minha função, mas a professora, ela fala assim, 'como você é minha auxiliar, eu tirei cópia de tal atividade, só que não está dando para enxergar, então você vai passar a caneta'...então assim, se eu não faço...

Prof. Pesq.: então e nesse momento você não está com o aluno LU?

Est. N.: ele está do meu lado, mas ele está fazendo a lição dele.

Encontro: 16.05.2017

Participantes: estagiária A.L., estagiária G., estagiaria D, professora pesquisadora.

[...].

Prof. Pesq.: Comenta que em outro grupo de estudo que participa, uma das estagiarias conta que quando a estagiaria não vai a criança com deficiência chega na escola e a escola pede para voltar para a casa porque não tem alguém para ficar com a criança.

Est. A.L.: É o que acontece comigo. Porque assim, ela (aluna A.B., com diagnóstico de deficiência intelectual) só vai se eu vou.

Nesses fragmentos seguimos analisando os dilemas que permeiam a realização da atividade das estagiárias. B. G., V. e N. relatam sobre as atribuições que desempenham como estagiárias e apontam algumas tensões que enfrentam. Pelos seus dizeres, inferimos que não há uma clareza sobre tais tarefas: estão lá para ajudar, mas não podem ajudar; acompanham alunos com deficiência, mas não devem conversar com as famílias; não devem auxiliar somente os alunos com deficiência, mas os professores as designam para realizarem atividades com esses alunos.

Se por um lado, a contração de estagiários pelas redes de ensino se apresenta como uma iniciativa voltada para a oferta de condições necessárias para a permanência do alunado da educação especial na escola e para o seu acesso a aprendizagem escolar, por outro lado, notamos que a função das estagiárias demanda maior definição. Há contradições entre as prescrições que Revista Interinstitucional Artes de Educar. Rio de Janeiro, V. 4, N.1- pág. 79 - 100 - (jan. - abr. de 2018): "Questões contemporâneas sobre a Educação Especial na Perspectiva da Educação Inclusiva" - 
recebem dos profissionais responsáveis pelos seus estágios e as tarefas que realizam em sala de aula, muitas vezes, denotando um deslocamento das funções dos professores regentes para as estagiárias (PRIETO, ET AL, 2014). Evidencia-se também contradições nas próprias recomendações dadas pela equipe formadora do centro educacional - "eles (equipe do centro) falam que a gente não pode ficar exclusivamente com o aluno especial, isso foi contratado no primeiro dia, e agora eles falam, você é auxiliar, o professor quer que a gente faça uma lição, a gente é obrigada a fazer...”. Nestas condições, as estagiárias acabam se tornando as responsáveis pelos alunos com deficiência na escola. A dependência criada chega ao ponto de a escola impedir a permanência desse alunado na ausência da estagiaria.

Diante da ambiguidade das recomendações recebidas nos encontros de orientação ofertados pela equipe do centro educacional, e das demandas colocadas pelas escolas e pelos professores, o funcionamento do estágio extracurricular tende a não ser bem compreendido pela comunidade escolar, acarretando, assim, problemas para a sua implantação. Com isso, os espaços de participação e os papeis a serem desempenhados pelas estagiárias na sala de aula acabam ficando a critério das relações interpessoais estabelecidas com a professora regente ou seguem as indicações da equipe gestora da escola.

Por um lado, as professoras solicitam auxílio das estagiárias para assumirem tarefas pedagógicas (desenvolverem atividades, aplicarem provas), pois também se veem em um dilema diante da necessidade de atenderem a todos os alunos e, ao mesmo tempo, darem conta das singularidades de cada um (PADILHA, 2011); por outro lado, realça-se nos dizeres das estagiárias a imagem produzida do seu (não) lugar na relação de ensino, daquela que não pode opinar, “dar ideia", que não pertence ao grupo escolar.

A relação estabelecida com a professora nas condições de estágio extracurricular configura-se como um espaço importante de aprendizado e de reflexão do trabalho pedagógico para algumas estagiárias, como vimos no primeiro segmento; mas, também, estabelece-se como lócus de conflito. A falta de clareza sobre as funções e atribuições traz angústias e inseguranças às estagiárias. Ora se veem como desempenhando funções que não fazem parte das recomendações, chegando ao ponto de se tornarem as responsáveis pela permanência do aluno com deficiência na escola; ora se veem como dispensáveis na dinâmica escolar - "Para o professor a gente não é nada"; "Para eles (equipe do centro) a gente só está lá de enfeite sabe".

Encontro: 08.08.2017.

Contexto: As estagiarias comentam sobre o acompanhamento das crianças com deficiência. A est. B. compartilha uma situação vivida na escola com o aluno W., com deficiências intelectual e 
auditiva e epilepsia. Este aluno tem tido frequentes crises convulsivas durante o período em que está na escola.

Est. B.: Eu não posso fazer nada que o médico não tenha mandado, porque como tá recaindo, a mãe falou para seguir aquilo, caso contrário pode ter uma piora, então não é pra fazer nada fora daquilo. Só que comendo, não dá pra mim deitar ele e virar a cabeça, porque a comida ainda tá aí, e ele saliva muito, então fica aquela saliva com a comida, fica uma pastinha aqui. E hoje ele engasgou comendo e como eu não posso servir ele, não posso forçar a abertura da boca dele, não posso nem fazer método de engasgamento, [...] de pressionar, só eu não posso fazer isso porque o ossinho dele é fraco e ele tem problema para respirar. Se eu fizer isso errado piora (voz trêmula). Aí eu pedi para a inspetora me ajudar, aí a gente tem que erguer, só que a gente não pode, o protocolo médico foi muito [...], aí a gente levou para a coordenação correndo, aí ligou pra ambulância. Aí ele começa a ficar roxo e você tenta fazer qualquer coisa, porque quando dá crise de ausência, ele não respira pelo nariz, ele respira só pela boca. [...] só que a ambulância demora um século até chegar, aí a hora que a gente estava no meio do caminho, ele tinha voltado. Aí a gente ligou para a mãe, perguntou se queria que levasse ao médico. A mãe falou que não, que estava normal. Aí depois na saída, ele teve mais uma. Ele estava sentado quietinho, foi indo, aí eu levantei, deitei ele no chão, ele se debateu muito, salivou, salivou, salivou. [...]. E agora ele está grunhindo, acho que a respiração dele está ficando difícil, ele grunhe, como se estivesse doendo. E aí tipo, eu não sei se para todo mundo é assim, mas lidar com inclusão me parece uma pressão invisível (voz trêmula), porque tipo parece que tudo cai na gente, tipo se ele não tem sucesso escolar, provavelmente não foram vocês que deram o apoio, se ele passa mal, se ele cair, foram vocês que não cuidaram, ninguém te fala isso, mas você sente toda hora, toda hora. Não sei se com vocês é assim, mas eu... (chora). Todo mundo está esperando que eu alfabetize ele, e cada vez que ele está tendo a crise, está piorando [...], eu não estou sabendo lidar. (Chora). [...]. Eu não sei se todo caso de inclusão é assim, mas eu tenho quase certeza que eu não vou conseguir trabalhar com inclusão.

Prof. Pesq.: Não tem que ficar tudo sobre você. Então a primeira coisa, vamos retomar o seu papel, você está como estagiária. Quem são as pessoas responsáveis por você no estágio? São as pessoas do centro educacional? Você já conversou isso com elas?

Est. B.: Já, e elas falaram que é um caso normal, que eu não tenho que me preocupar com isso. Só que a professora da sala já fez uma solicitação à mãe, pediu pra mãe fazer um documento falando que tinha total conhecimento das consequências de manter a criança lá, porque não tem condição ética para aquilo. Mas, sei lá, toda hora que ele convulsiona, todo mundo acha que eu sei (ininteligível), eu não sei o que passa na cabeça de todo mundo que eles olham pra mim como se eu entendesse...

No relato da estagiaria B. ressoa a vivência impregnada de conflitos produzidos nas atribuições implícitas assumidas no acompanhamento do aluno W., que afeta o modo como ela significa a inclusão escolar e que ecoa no processo de sua constituição docente.

Explicita-se em seu dizer o dilema entre seguir as recomendações médicas e 'salvar' o aluno que engasgou e não está conseguindo respirar, sem ter para tanto um preparo específico (“eu não posso fazer nada que o médico não tenha mandado"; "aí a gente tem que erguer, só que 
a gente não pode"); a aflição pela espera da ambulância que demora a chegar ("só que a ambulância demora um século até chegar"); a complexa relação com a família ("aí a gente ligou para a mãe, perguntou se queria que levasse ao médico. A mãe falou que não, que estava normal"); o desamparo da equipe responsável pela orientação ("elas falaram que é um caso normal, que eu não tenho que preocupar com isso"); a tensão sentida ao ser responsabilizada pelos cuidados com o aluno e também por seu (in)sucesso escolar ("lidar com inclusão me parece uma pressão invisível, porque tipo parece que tudo cai na gente"; "eu não sei o que passa na cabeça de todo mundo que eles olham pra mim como se eu entendesse").

A imagem da estagiária que circula na ambiência escolar está associada aos profissionais do centro educacional, responsáveis pela educação especial do município. A equipe da escola espera da estagiária um saber fazer e um conhecimento específico em relação à questão da deficiência. Delega-se, portanto, a ela o caso do aluno W.

Com isso, a posição de estagiária que B. ocupa na escola condensa diferentes papeis sociais relacionados à assistência necessária ao processo de escolarização do aluno com deficiência: o papel da cuidadora (alimenta, socorre), da professora de educação especial (fornece apoio específico), da professora regente (alfabetiza). Vivencia múltiplos papeis, participa da produção de sentidos da sua posição, se constitui imersa numa complicada trama de relações e acontecimentos.

A noção de drama elaborado por Vigotski (1929/2000b) nos ajuda a compreender como as relações sociais vividas, os múltiplos sentidos produzidos, as tensões que perpassam os diferentes papeis exercidos nas práticas tornam-se constitutivas da singularidade, dos modos de sentir, de agir, de pensar, e como interfere no sentido da atividade. Nas palavras de Delari Júnior (2011), o drama no sentido vigotskiano pode ser definido enquanto "processo social tenso, dramático, repleto de escolhas entre agir ou não agir" (p. 190). Nestes termos, podemos dizer que B., vivencia o drama entre o fazer e não fazer, entre o agir e o não agir, entre o saber e o não saber. Essas vivências conflituosas produzidas nessas condições incidem no sentido da atividade pedagógica. O vivido na posição de estagiária reverbera na ação prospectiva enquanto docente, a ponto de B. significar negativamente o trabalho pedagógico com alunos com deficiência - "eu não sei se todo caso de inclusão é assim, mas eu tenho quase certeza que eu não vou conseguir trabalhar com inclusão".

Alunos que realizam estágio precisam encontrar um espaço de diálogo em um grupo de formação, para ser possível fazer a mediação entre os acontecimentos que envolvem a prática pedagógica e as questões teóricas (OLIVEIRA, PINTO, 2011). B. cursa o primeiro ano de licenciatura em Pedagogia e teve contato com aspectos teóricos mais gerais; até o momento as Revista Interinstitucional Artes de Educar. Rio de Janeiro, V. 4, N.1- pág. 79 - 100 - (jan. - abr. de 2018): "Questões contemporâneas sobre a Educação Especial na Perspectiva da Educação Inclusiva" - 
disciplinas cursadas não possibilitaram uma discussão sobre a problemática que envolve a educação especial, de forma mais consistente. A estagiária B. está vivenciando condições concretas da inclusão de alunos com deficiências na escola, que envolvem questões complexas como a relação saúde e educação e os conflitos familiares. Isso demandaria espaços de elaboração e formação para reflexão crítica e analítica das questões provenientes dessa prática social.

Como veremos na situação a seguir quando a estagiaria, no âmbito da formação acadêmica (grupo de estudos), vivencia um lugar de escuta, de interlocução sobre os dilemas vividos na prática, novas possibilidades de participação na dinâmica da aula se produzem. Ela encontra um respaldo para dialogar e argumentar com a professora sobre outros modos de atuação na sala e contribuição na prática pedagógica.

Encontro: 02.05.2017.

Participantes: estagiária G., estagiária V., estagiária N., professora pesquisadora.

Contexto: A estagiária G. comenta sobre a aluna L. (com deficiência intelectual e autismo) que acompanha. Conta que a aluna L. se recusa a tentar aprender a amarrar o sapato, a apontar o lápis, e delega essa tarefa a ela.

Est. G.: Eu vejo que ela (aluna com deficiência intelectual e autismo) acha que eu estou lá para servir ela. Eu sou a baba dela que devo fazer tudo para ela. [...]. Eu conversei com a professora e a professora também acha melhor, a professora ficar mais com a L. e eu ficar mais com o restante da sala. [...].

$[\ldots]$

Prof. Pesq.: E aí, as atividades? As demais atividades?

Est. G.: Eu passo atividade diferenciada, porque esse é o sistema que a professora achou melhor. No primeiro encontro, referente ao dia 18/04/2017, que não foi audiogravado, mas foi registrado em caderno de pesquisa pela professora pesquisadora, a estagiária conta que a professora tem uma pasta com tarefas prontas para a aluna com deficiência e pede para ela, a estagiária, escolher uma das tarefas e desenvolver com a aluna. A escolha fica a critério da estagiária e nem sempre está relacionada com o tema trabalhado pela turma.

Encontro: 16.05.2017

Participantes: estagiária A.L., estagiária G., estagiaria D, professora pesquisadora.

Contexto: A estagiária G. conta sobre a aluna L. com autismo e deficiência intelectual que acompanha no $2^{\circ}$. ano do Ensino Fundamental.

Est.G.: Eu conversei com a professora, falei pra ela das dicas que você falou, porque a professora é muito gente boa assim, eu sempre falo com ela as coisas e daí ela concorda com as minhas ideias e tal. Daí eu falei pra ela das dicas que você me deu [...] e daí agora eu não estou mais sentando ao lado da L., estou sentando na frente da sala. Então, por exemplo, aqui é a mesa da professora e eu sento aqui, juntei duas mesas de criança e sento [...]. Agora eu estou mais como auxiliar da classe e menos da L. A professora está focando na L. e nas outras crianças que tem 


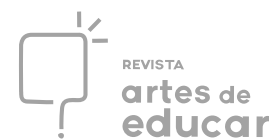

dificuldades, porque tem alguns que não são alfabéticos ainda. $\mathrm{E}$ eu, tipo ela passa a atividade na lousa para todo mundo e daí ela foca nos que tem dificuldades e eu vou passando nos outros.

Destacamos nesses trechos possibilidades de transformação das relações produzidas entre a estagiária G. e a professora regente, e como influiu nas funções da estagiária na dinâmica da aula, bem como nas formas de organização do trabalho da professora.

Em um primeiro momento, G. tem o acompanhamento restrito à aluna L., com deficiência intelectual e autismo, gerando, inclusive, uma acomodação da aluna em relação às tarefas que tem que efetuar. G. conta que a professora prepara atividades diferenciadas para a aluna, e fica a seu critério a seleção das atividades que serão realizadas a cada dia. A estagiária acaba vivenciando com a aluna com deficiência uma prática de ensino paralelo ao que está sendo trabalhado com o restante da turma, seguindo na contramão daquilo que vem sendo preconizado pelas políticas educacionais vigentes (PLESTCH, 2014).

O estágio extracurricular é importante por aproximar o aluno de pedagogia da realidade do cotidiano escolar; entretanto, se não houver um espaço para que seja discutido com G. os sentidos desse modo de organizar o trabalho pedagógico em relação ao aluno com deficiência, essa importância se esvai.

Com base na discussão feita no grupo de estudos na universidade, a estagiária G. relata que conversou com a professora sobre esse fato e combinaram um novo modo de atuação, deslocando de G. a função exclusiva de acompanhar a aluna L.. Por meio do diálogo e do enfrentamento conjunto dos desafios cotidianos, foi possível estabelecer outro modo de participação da estagiária na dinâmica da aula, o que viabilizou uma nova forma de organização do trabalho pedagógico da professora regente, orientado para a atenção mais específica à diversidade.

Com isso, muda, até mesmo, o lugar físico ocupado pela estagiária: deixa de sentar ao lado da aluna com deficiência e senta-se ao lado da mesa da professora; o que é indicativo da transformação do modo de atuação. A estagiária não auxilia exclusivamente a aluna com deficiência, mas contribui com o trabalho da professora, auxilia a classe. A professora, por sua vez, não propõe mais atividades diferenciadas e descontextualizada à aluna com deficiência, e sim tem condições de a incorporar na proposta de atividade comum da turma, fornecendo apoio e atenção específica.

\section{Das percepções de ensino-aprendizagem de alunos com deficiência}


Encontro: 02.05.2017.

Participantes: estagiária G., estagiária M., estagiária V., estagiária N., professora pesquisadora.

Contexto: Estagiária G. conta sobre a aluna L. com deficiência intelectual e autismo que acompanha no $2^{\circ}$. ano do Ensino Fundamental.

Est. G.: Ela (aluna L.) se recusa a fazer (a atividade escolar). Ela fala 'Eu não quero', 'Eu não consigo'. Isso me intriga muito quando ela fala 'não consigo', porque eu sei que ela consegue.

[...]. Eu falo pra ela 'Você consegue sim'.

$[\ldots]$

Contexto: Estagiária V. conta sobre o aluno L.G. com paralisia cerebral que acompanha na primeira fase em uma CEMEI.

Est. V.: De momento foi passado pra mim (centro educacional) que 'ele não faz nada', 'ele não sabe andar direito', 'ele não sabe falar', 'ele não gesticula direito', tudo pessimismo, sabe? Então eu fui para a escola daquele jeito, nossa ele é cadeirante, ele não faz nada, eu vou ter que ajudar em tudo. Aquele pensamento de que eu não sei nada e como eu vou fazer? [...]. Daí eu fui um dia antes para mim conhecer e ver se eu vou aguentar o pank, né? Eu fui lá, vi, e gostei. Por mais que eu não tive muito contato com ele (a criança com paralisia cerebral), eu vi que não era tudo aquilo. Aí eu comecei a ir, comecei a ir. Aí a gente começou a melhoria, mas eu acabo aprendendo mais com ele do que ele comigo, porque as coisas que acontecem, eu fico impressionada, sabe? É uma criança que é muito visual, ele olha muito para os amiguinhos e imita [...]. Tá na merenda, e daí ele olha para a criança, a criança está assim e daí ele vai e faz assim. Só que ele não sabe fazer muito bem direito. Eu tenho que ajudar, elevar a mãozinha na boca pra ele comer. [...]. Ele anda, mas um pouquinho diferente, não tem muito equilíbrio. Ele consegue até comer. A fala dele é assim, ele não fala, só que ele tenta. Ele está começando a tentar falar, nossa isso é incrível! A professora está lá explicando 'Olha pessoal, a gente vai fazer essa atividade', daí ele fala 'Aaa-ti-vi-da-de' (pausa entre sílabas). [...]. Ele usa gestos. [...]. Eu sinto que ele responde com o corpo, sabe? [...]. Ele entende muito, muito mesmo.

Os dizeres das estagiárias G. e V. sobre suas percepções em relação ao ensinoaprendizagem dos alunos L. e L.G. mostram que elas têm um olhar orientado para as possibilidades de desenvolvimento e escolarização dos alunos com deficiência: acreditam que eles podem aprender, encorajam os alunos na realização da atividade escolar, compreendem que também aprendem na relação com eles, percebem positivamente o modo como os alunos participam das atividades (falar, imitar, gestualizar), estão atentas às especificidades dos alunos, observam os ganhos no processo de ensino-aprendizagem.

Isto nos remete às ideias de Vigotski (1997) a respeito dos processos de aprendizagem de pessoas com deficiências. Com base no princípio da natureza social do desenvolvimento e adotando uma concepção dinâmica e dialética de deficiência, o autor enfatizou a importância das condições de desenvolvimento orientadas para a participação ativa e integral da pessoa com deficiência na sociedade. Destacou que as formações psicológicas não são determinadas organicamente, e estão intrinsecamente relacionadas às possibilidades sociais. Dizendo de outro 
modo, as formações psicológicas, incluindo, linguagem oral, linguagem escrita, dentre outras, são resultantes da apropriação das funções sociais, compartilhadas e exercidas conjuntamente nas práticas educacionais (VIGOTSKI, 1995, 1996). O olhar para as possibilidades de desenvolvimento, a atenção para as especificidades, a importância da produção e disponibilização de recursos, o apoio específico, a mediação pedagógica pautada na criação de situações que promovam novas formações psicológicas, são teses que ecoam muito fortemente na contemporaneidade e que nos ajudam a pensar na formação inicial de professores e nas condições de escolarização de alunos com deficiência no contexto da educação inclusiva.

A respeito da educação de pessoas com deficiências há um modo de conceber - que historicamente perpassa os modos de organização de ensino para essas pessoas - que focaliza o núcleo orgânico da deficiência, os limites e impedimentos de natureza biológica, em detrimento das possibilidades de aprendizagem ofertadas pela inserção da criança nas práticas sociais, escolares. A estagiária V. conta que a descrição do aluno com deficiência dada pela equipe de especialistas do centro educacional pautou-se na falta das funções e nas incapacidades de aprendizagem do aluno. A sensação frente a isso foi de hesitação, medo, levando-a ponderar, até mesmo, a desistência do estágio. Na relação com o aluno, foi se sensibilizando e se surpreendendo com as possibilidades de participação dele nas práticas de ensino, com o interesse e o esforço desempenhado e com a atenção orientada às atividades escolares. A estagiária atentase aos mínimos gestos do aluno, compreende as especificidades de ordem orgânica e aposta nas possibilidades educacionais. Ajuda-o a realizar alguns movimentos e interpreta suas ações positivamente, auxiliando no processo de ensino-aprendizagem orientado para a criação de novas formações psicológicas.

Encontro: 16.05.2017

Participantes: estagiária A.L., estagiária G., estagiaria D, professora pesquisadora.

Contexto: A estagiária A.L. conta sobre a aluna A.B com deficiência intelectual na aula de matemática em uma turma do $5^{\circ}$. ano do ensino fundamental.

Est. A.L.: Toda quinta, é quinta do desafio, então ela sempre traz um desafio para as crianças. E quinta passada foi desafio do pim pam pum, que é o seguinte, números pares ou múltiplos de dois, a gente substitui por pim, então seria 1, pim, 3, pim, 5, pim e assim vai. E quem errasse ia saindo. O pam múltiplo de 3 e o pum múltiplo de 6. A A.B. ganhou o jogo, em uma sala de 26 alunos. A professora vinha apontando assim ó, por exemplo, 24,o próximo é 25, aí ela falava 25 , ou 23, o próximo era 24, aí ela pim. Ela conseguiu associar o par.

[...].

Est. A.L.: Uns três dias antes a psicopedagoga foi lá e a gente conversou tudo, ela perguntou da A.B. Aí eu acabei comentando com ela sobre a aula de matemática, que a gente estava tentando desenvolver [...] com ela a parte da matemática, vezes, soma, subtração. [...]. E a psicopedagoga 


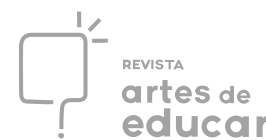

disse assim 'Vocês não podem tentar desenvolver assim, porque já foi testado com ela e ela não desenvolveu, então ela não vai desenvolver, então é pra ela usar a calculadora'. Aí três dias depois, ela (A.B) consegue ganhar o jogo desse jeito.

$[\ldots]$

Est. A.L.: Na verdade, o que a gente tá fazendo? A gente até deixa ela usar a calculadora, mas depois que ela faz a conta, pra ela conferir, se fez certo ou errado.

Seguimos focalizando os modos como as estagiárias percebem os alunos com deficiência. Nesse trecho, a estagiária A.L. relata sobre a participação da aluna A.B., com deficiência intelectual, durante a realização de uma atividade que envolve um raciocínio matemático. A professora propõe um desafio para toda a turma, e a aluna A.B. não só participa, como vence o desafio. Nessa situação, a aluna A.B. está inserida em uma prática pedagógica que não acontece à parte da dinâmica de toda a sala de aula. A forma de a professora organizar o trabalho pedagógico contribui para que a estagiária A.L. possa ir construindo uma concepção mais prospectiva a respeito da inclusão escolar de alunos com deficiências.

Com base nesse trecho, apontamos ainda para os diferentes modos de compreensão da aluna com deficiência por parte dos educadores. A professora insere a aluna na atividade, a instigando para o desafio; todavia, a psicopedagoga apresenta uma orientação que não viabiliza a criação de caminhos para ampliar o desenvolvimento do pensamento matemático da criança com deficiência intelectual. Os dizeres da estagiaria permitem inferir que para a psicopedagoga a aluna com deficiência intelectual não seria capaz de realizar uma atividade que envolvesse um pensamento lógico-abstrato sem o auxílio da calculadora. Já a professora acredita na possibilidade de desenvolvimento intelectual, convocando a aluna para o desafio matemático que pressupõe conhecimentos relativos ao $5^{\circ}$. ano do ensino fundamental.

No relato da estagiária A.L. há indícios de que a relação entre ela e a professora é bastante profícua - notamos o uso da expressão "a gente", ao se referir ao modo como ela e a professora estão realizando o trabalho educacional. Inferimos que o desenvolvimento do trabalho em parceria entre a estagiária e a professora torna-se condição para a ressignificação das percepções sobre as possibilidades de ensino-aprendizagem de alunos com deficiência intelectual.

\section{Considerações finais}

Este estudo tende a corroborar com achados de trabalhos supracitados que constatam que, no processo de implementação das políticas educacionais inclusivas, uma das ações que tem se 
destacado no âmbito dos municípios, no sentido de subsidiar o trabalho pedagógico na diversidade, é a contratação de estagiários, sobretudo, dos cursos de Pedagogia. São ainda poucas as pesquisas acerca desse assunto. Considera-se que sua complexidade demanda atenção e discussão, merecendo desdobramento investigativo.

A partir das análises dos dizeres das estagiárias que refletem as suas vivencias na escola, podemos compreender os dilemas que perpassam a configuração do estágio extracurricular. As orientações recebidas em relação as suas funções não coincidem com as atribuições que vêm assumindo no espaço escolar. Explicitam-se ambiguidades nas próprias prescrições, bem como divergências entre o prescrito e o realizado da atividade, aspectos esses associados aos problemas referentes à definição da proposta de estágio extracurricular e a sua implantação tecida na tensão com as demandas concretas da escola.

Muitas vezes o que se observa é que as alunas estagiárias não se veem pertencentes à dinâmica escolar e se sentem ocupando um não lugar nas práticas educacionais; outras vezes, nota-se que ao invés de assessorarem o trabalho da professora com a turma, acabam assumindo os cuidados específicos e o ensino dos alunos com deficiência. Isso pode gerar alguns problemas como: a desresponsabilização da professora regente pelo planejamento e execução das atividades de ensino de modo a assegurar a participação de todos os alunos; a não contratação de profissionais especializados para os cuidados específicos (alimentação, higienização, primeiros socorros) que alguns casos demandam; a ausência de um trabalho conjunto entre professores de educação especial e professores regentes para o acompanhamento sistemático do processo de ensino-aprendizagem de alunos com deficiência na sala de aula tendo em vistas o atendimento de suas especificidades; o silenciamento sobre a diminuição de números de alunos por turma. Neste sentido, a contratação de estagiários parece não resolver as questões relativas às condições de trabalho do professor e à forma de organização da escola, a fim de garantir a qualidade da escolarização de alunos com deficiência.

Observamos como, no âmbito do estágio extracurricular, os aspectos envolvidos na constituição inicial da docência se entretecem à rede de demandas e expectativas que circunscrevem a prática escolar produzida no contexto das políticas de educação inclusiva. Nessas condições, as alunas estagiárias vivenciam tensões e conflitos que incidem no sentido da atividade de ensinar e permeiam o processo da formação inicial, suscitando efeitos no envolvimento com a profissão e gerando (im)possibilidades de desenvolvimento de novas ações.

Sendo assim, a organização do estágio extracurricular requer uma estrutura que viabilize condições de reflexão do vivido articulado à teoria de modo a ancorar a participação dos estagiários nas práticas escolares por meio da efetivação da práxis educativa. 
Tendo isso em vista, a universidade, no âmbito da formação acadêmica, tem função fundamental na sustentação dessa relação teoria e prática. O espaço do grupo de estudos pode ser tomado como lócus de co-laboração e e-laboração do vivido, em que as estagiárias encontram possibilidades de narrarem suas experiências, relatando receios e inquietudes em relação ao seu papel e às práticas pedagógicas das quais participam. Nessa dinâmica, percepções são compartilhadas, modos de compreensão são constituídos, conceitos são elaborados, embasando novas formas de reflexão e atuação.

Consideramos, portanto, que a vivência nas práticas escolares em consonância com a análise do vivido, desenvolvida com articulação teórica no âmbito do grupo de estudos na universidade, torna possível a sensibilização do olhar; as alunas estagiárias percebem os gestos mínimos reveladores dos processos de ensino-aprendizagem. As percepções que vão sendo constituídas se orientam para as possibilidades do trabalho pedagógico e para as potencialidades de desenvolvimento de alunos com deficiência.

\section{Referências}

BAKHTIN, M. Marxismo e Filosofia da Linguagem. $7^{\text {a }}$ ed. São Paulo: Hucitec, 1995.

BAKHTIN, M. Estética da Criação Verbal. $4^{\mathrm{a}}$ ed. São Paulo: Martins Fontes, 2003.

BARRICELLI, E.; DAINEZ, D.; SMOLKA, A.L.B. Educação inclusiva no contexto da educação infantil: o trabalho pedagógico em foco. Comunicações, Piracicaba, v.23, p.151-166, 2016.

BRASIL. Ministério da Educação. Conselho Nacional da Educação. Câmara de Educação Básica. Parecer n. 17, de 3 de julho de 2001. Diretrizes Nacionais para a Educação Especial na Educação Básica. Diário Oficial da União, Brasília, DF, 17 ago. 2001. Seção 1, p. 46.

Disponível em: <http: //www.portal.mec.gov.br/seesp/arquivos/pdf/parecer17.pdf >. Acesso em: junho de 2017.

BRASIL. Ministério da Educação. Secretaria de Educação Especial. Programa Educação Inclusiva: direito à diversidade. Brasília, DF: MEC/ SEESP, 2005. (Documento orientador). Disponível em: <http://www.mec.gov.br>. Acesso em: julho de 2017.

BRASIL. Ministério da Educação. Secretaria de Educação Especial. Política Nacional de Educação Especial na perspectiva inclusiva. Brasília, DF: MEC/SEESP, 2008. Disponível em: <http://www.mec.gov.br>. Acesso em: junho de 2017.

DELARI JÚNIOR, A. Sentidos do "drama” na perspectiva de Vigotski: um diálogo no limiar entre arte e psicologia. Psicologia em Estudo, Maringá, v. 16, n. 2, p. 181-197, abr./jun. 2011. Disponível em: http://www.scielo.br/pdf/pe/v16n2/a02v16n2.pdf. Acesso em: 13 ago. 2017. 
GARCIA, R.M.C. Políticas inclusivas na educação: do global ao local. In.: BAPTISTA, C. R.; CAIADO, K. R. M.; JESUS, D.M. (Orgs.). Educação Especial: diálogo e pluralidade. Porto Alegre: Mediação, 2008, p.11-24.

JANNUZZI, G. de M. A luta pela educação do deficiente mental no Brasil. São Paulo, SP: Cortez: Autores Associados, 1985.

KASSAR, M. C.M. Escola como espaço para a diversidade e o desenvolvimento humano. Educação e Sociedade, Revista de Ciências da Educação, v.37, n.137, p.1223-1240, 2016.

OLIVEIRA, C. A. Municipalização do ensino brasileiro. In: OLIVEIRA, C. et al. (orgs.) A Municipalização do ensino no Brasil: algumas leituras. Belo Horizonte: Autêntica, 1999. p.1136.

OLIVEIRA, A.A.S.O.; LEITE, L. P. Construção de um sistema educacional inclusivo: um desafio político-pedagógico. Ensaio: Avaliação e Políticas Públicas em Educação. Rio de Janeiro, v. 15, n.57, p.511-524, 2007. Disponível em:

http://www.scielo.br/pdf/ensaio/v15n57/a04v5715.pdf. Acesso em 16 ago. 2017

OLIVEIRA, I.M.; PINTO, A.K.P. Estágio extracurricular e formação em educação especial. In.: CAIADO, K.R.M.; JESUS, D.M., BAPTISTA, C.R. (orgs.) Professores de educação especial: formação em foco. Porto Alegre: Mediação, 2011, p.105-124.

OLIVEIRA, A. A. S.; DRAGO, S. L. S. A gestão da inclusão escolar na rede municipal de São Paulo: algumas considerações sobre o Programa Inclui. Ensaio: aval. pol. públ. Educ., Rio de Janeiro, v. 20, n. 75, p. 347-372, abr./jun. 2012 Disponível em:

http://www.scielo.br/pdf/ensaio/v20n75/07.pdf. Acesso em 10 ago. 2017

PADILHA, A. M. L. Trabalho pedagógico: conhecimento, experiência e formação. In: VICTOR, S. L.; DRAGO, R.; CHICON, J.F. (org.) Educação Especial e Educação Inclusiva: conhecimentos, experiências e formação. Araraquara: Junqueira \& Marin, 2011, p. 104-114.

PESSOTTI, I. Deficiência mental: da superstição à ciência. São Paulo: EDUSP, 1984.

PLETSCH, M.D. Repensando a inclusão escolar: diretrizes políticas, práticas curriculares e deficiência intelectual. 2ed., rev. e ampl. Rio de Janeiro: NAU, 2014.

PRIETO, R.G. et al. Políticas de inclusão escolar no Brasil: descrição e análise de sua implementação em municípios em diferentes regiões. In.: XXVII Reunião Anual da ANPED, Caxambu, 2004. Disponível em: www.anped.org.br. Acesso em 10 junho de 2017.

PRIETO, R. G.; PAGNEZ, K.S.M.M.; GONZALEZ, R.K. Educação especial e inclusão escolar: tramas de uma política em implantação. Educação \& Realidade. Porto Alegre, v.39, n.3, p.725-743, 2014.

TEZZARI, M.L.; BAPTISTA, C.R. A medicina como origem e a pedagogia como meta da ação docente na educação especial. In.: CAIADO, K.R.M.; JESUS, D.M., BAPTISTA, C.R. (orgs.) Professores de educação especial: formação em foco. Porto Alegre: Mediação, 2011, p.19-34. 
VIGOTSKI, L.S. A construção do pensamento e da linguagem. São Paulo: Martins Fontes, 2000a.

VIGOTSKI, L. S. Manuscrito de 1929. Educação e Sociedade. V. 71. Número especial, 2000b, p. 21-44.

VYGOTSKI, L. S. Obras escogidas. V. 3. Madrid: Visor. 1995.

VYGOTSKI, L. S. Obras escogidas. V. 4. Madrid: Visor. 1996.

VYGOTSKI, L. S. Obras escogidas. V. 5. Madrid: Visor. 1997.

${ }^{i}$ Mestre e Doutora em Educação, pela Universidade Estadual de Campinas (1996; 2001). Professora do Programa de Pós-Graduação Stricto Sensu em Educação, da Universidade São Francisco, Itatiba, na linha Educação, Linguagens e Processos Interativos

ii Doutorado na área Psicologia Educacional pela UNICAMP, nos anos de 2014 a 2016 realizou uma pesquisa de Pós-Doutorado no Grupo de Pesquisa Pensamento e Linguagem da UNICAMP com apoio financeiro da FAPESP. 